\title{
Prevalence and Assessment of Potentially Inappropriate Medications among Lebanese Elderly inpatients
}

Mohamed Hendaus ( $\nabla$ mohamed.hendaus@liu.edu.lb )

Lebanese International University

\section{Alissar Chirazi}

Lebanese International University

\section{Maya Hassan}

Lebanese International University

Nisreen Mourad

Lebanese International University

\section{Samar Younes}

Lebanese International University

Mahmoud Moussa

Bekaa Hospital

\section{Mohamad Rahal}

Lebanese International University

\section{Research Article}

Keywords: PIMs, pharmaceutical care, elderly, Beer's criteria, geriatrics

Posted Date: March 18th, 2021

DOl: https://doi.org/10.21203/rs.3.rs-318181/v1

License: (9) This work is licensed under a Creative Commons Attribution 4.0 International License.

Read Full License 


\title{
1 Prevalence and Assessment of Potentially Inappropriate Medications among 2 Lebanese Elderly inpatients
}

Mohamed Hendaus, PharmD ${ }^{1 *}$, Alissar Chirazi ${ }^{4}$, Maya Hassan ${ }^{4}$, Nisreen Mourad, PharmD, MSc ${ }^{1}$, Samar Younes, PharmD, $\mathrm{MSc}^{3}$, Mahmoud Moussa, $\mathrm{MD}^{5}$, Mohamad Rahal, $\mathrm{PhD}^{2}$

${ }^{1}$ Department of Pharmacy Practice, School of Pharmacy, Lebanese International University, Bekaa, Lebanon

${ }^{2}$ Department of Pharmaceutical Sciences, School of Pharmacy, Lebanese International University, Bekaa, Lebanon

${ }^{3}$ Department of Biomedical Sciences, School of Pharmacy, Lebanese International University, Bekaa, Lebanon

${ }^{4}$ PharmD Department, School of Pharmacy, Lebanese International University, Bekaa, Lebanon

${ }^{5}$ Department of Surgery and Anesthesiology, Bekaa Hospital, Bekaa, Lebanon

\author{
Mohamed Hendaus, PharmD \\ Clinical Instructor \\ School of Pharmacy - Lebanese International University, Bekaa, Lebanon \\ Tel.: +96171405505 \\ Email: mohamed.hendaus@liu.edu.lb \\ (iD) https://orcid.org/0000-0002-0432-5190
}

\author{
Alissar Chirazi, PharmD \\ Pharmacy Intern \\ School of Pharmacy - Lebanese International University, Bekaa, Lebanon \\ Email:81430008@students.liu.edu.lb

\section{Maya Hassan, PharmD} \\ Pharmacy Intern \\ School of Pharmacy - Lebanese International University, Bekaa, Lebanon \\ Email: 21430765@students.liu.edu.lb \\ Nisreen Mourad, PharmD, MSc \\ Assistant Professor \\ School of Pharmacy - Lebanese International University, Bekaa, Lebanon \\ Email: nisreen.mourad@liu.edu.lb
}

\section{Samar Younes, PharmD, MSc}

Assistant Professor (Assistant Dean)

School of Pharmacy - Lebanese International University, Bekaa, Lebanon, Bekaa, Lebanon

Email: samar.younes@ liu.edu.lb

\section{Mahmoud Moussa, M.D}

Medical Doctor

Bekaa Hospital, Bekaa, Lebanon

Email: mahmoudsayedmoussa@gmail.com

\section{Mohamad Rahal, PhD}

Professor (Dean)

School of Pharmacy - Lebanese International University, Bekaa, Lebanon

Email: mohamad.rahal@liu.edu.lb 


\section{Prevalence and Assessment of Potentially Inappropriate Medications among 53 Lebanese Elderly inpatients}

54

55

56

57

58

59

60

61

62

63

64

65

66

67

68

69

\begin{abstract}
Background: Potentially inappropriate medications (PIMs) prescribing in older increases the risk of hospitalization, drugrelated problems, and other adverse health outcomes by two to three folds (Lu WH, 2015) (WHO, 2018). Hence several regulations have been implemented in geriatric clinical practice to improve drug appropriateness. This study aimed to assess the prevalence of PIMs identified by the Beers 2019 criteria among Lebanese elderly inpatients, and to identify the factors that may influence such inappropriateness. Methods: This observational study was conducted among elderly patients of 3 hospitals in Lebanon. Data were collected from patients using a questionnaire based on the 2019 Beers criteria. Descriptive statistics and multivariable logistic regression were used to describe and identify the predictors of PIMs use. Statistical analysis was carried out using the SPSS software version 22.0. Results: A total of 110 in-patients aging 65 years and older were analyzed. 80\% of patients were taking drugs that are considered PIMs to be avoided; The most commonly prescribed PIM was proton pump inhibitors (PPIs) (60\%). PIMs use was significantly associated with polypharmacy and other comorbid conditions ( $\mathrm{p}$-value $<0.05$ ). The prevalence of PIMs to be used with caution was $78.2 \%$, those having drug-disease interactions were $22.7 \%$ and those having clinically important drug-drug interactions were $15.5 \%$. Conclusion: A high prevalence of PIMs use in Lebanese hospitalized patients was observed, and was significantly associated with polypharmacy and other CNS conditions. This study supports the need for the implementation of clinical guidelines and staff to improve drug prescribing in older adults. Trial registration: retrospectively registered.
\end{abstract}

Key words: PIMs, pharmaceutical care, elderly, Beer's criteria, geriatrics

. (1) 2 . 


\section{Methods}

This cross-sectional observational study was conducted in three main Hospitals in Bekaa/ Lebanon within 8weeks duration. Data was collected from patients' profiles using the hospital's systems, and directly from patients or caregivers. Subjects were assessed by officially licensed Lebanese pharmacists who were trained to present and collect data in order to maintain its uniformity. Ethical approval was obtained from the School of Pharmacy at the Lebanese International University, and verbal informed consent was taken from the patients/ caregivers and from the 3 hospitals' administrations. A written informed consent was also obtained.

The questionnaire used was based on the 2019 Beers criteria, and was divided into three main parts: Demographic properties, Comorbidities/ disease states, and medications taken. Medications and co-morbidities were then classified into categories based on Beers' criteria division also, for example, medications were classified as: (1) medications to be avoided, (2) medications to be used with caution, (3) medications having drug-disease or drug syndrome interaction that 
may exacerbate the disease or syndrome, and (4) medications having clinically important drug-drug interactions that should be avoided. PIMs use also was classified into two categories: PIMs use, and no PIMs use. Data were coded and entered for analysis. Descriptive testing was used to summarize and describe subjects' related information; frequencies and percentages were used to describe demographic properties of patients and primary outcomes. Fisher exact test was used to determine statistical significance in the bivariate analysis between PIMs use and subjects' characteristics and comorbidities, while logistic regression was used in the multivariable analysis. The $95 \%$ confidence intervals (CI) were based on likelihood. All reported p-values were 2 -sided and considered significant if they were less than $<0.05$. Data were entered and analyzed using software IBM Statistical Package for Social Science (SPSS) version 20.

\section{Results}

During the eight-week study, 110 subjects were enrolled in the study by convenient sampling. Average age was $36.9 \pm$ 13.5 (range between 18 and 85 years), and the majority were females. Subjects above 65 years were divided according to age group, with 40 subjects aging between 65 and 69 years, 17 aging between 70 and 74 years, 13 aging between 75 and 79 years, and 38 aging more than or equal to 80 years. The majority of the study population had chronic conditions, particularly hypertension and diabetes [Figure 1]. The prevalence of polypharmacy was high among subjects (73.6\%) with significant associations. Detailed participants' socioeconomic data are presented in [Table 1].

The prevalence of PIMs in the tested population was 105 out of 110 (95.5\%) - one subject may have more than one type of PIM-, and was divided as follow: PIMs to be avoided (80\%), followed by PIMs to be used with caution (78.2\%), PIMs having drug-disease or drug syndrome interaction that may exacerbate the disease or syndrome (22.7\%) and PIMs having clinically important drug-drug interactions that should be avoided (15.5\%) [Table 2]. The most commonly prescribed PIMs to be avoided were gastrointestinal agents (particularly PPIs) followed by CNS acting drugs [Table 3]. The most commonly prescribed PIMs to be used with caution were antipsychotics (48.2\%), followed by diuretics (30.9\%), while aspirin and SSRIs were in equal proportions (15.5\%) [Table 4]. In regards to drug-disease interactions, the most commonly encountered drug-disease interactions were: 1) Falls with SSRIs (4.5\%), antipsychotics (3.6\%), BZDs (3.6\%), 2) Dementia with BZDs (4.5\%), antipsychotics $(4.5 \%), 3)$ Delirium with antipsychotics $(3.6 \%)$. Two main drug-drug interactions were noticed: the use of 3 or more CNS active drugs with a proportion of $14.5 \%$, followed by the concomitant use of 2 anticholinergics with a proportion of $1.8 \%$.

The prevalence of PIMs to be avoided was associated with different variables like marital status and polypharmacy, and conditions like hypertension, diabetes mellitus, falls and bipolar. Detailed percentages and $\mathrm{P}$ values are presented in [Table 5]. In the multivariate analysis, older adults with polypharmacy, and conditions like dementia, falls, insomnia, and schizophrenia were associated with PIMs. For example, $88.9 \%$ of patients who were taking more than or equal 5 drugs have a PIM to be avoided, while $11.1 \%$ don't $(\mathrm{P}$ value $=0.001)$ [Table 6]. Another example is in the case of falls, where $94.7 \%$ of patients suffering from this condition have PIMs to be used with caution, while $5.3 \%$ don't $(\mathrm{P}$ value $=0.05$ ). Adjusted odds ratios and $95 \%$ confidence intervals $(\mathrm{CI})$ for factors associated with PIMs use are presented in [Table 6]. 


\section{Discussion}

It is well known that PIMs use among older patients is associated with negative health consequences and can impact patients' quality of life, with increased hospitalization risk, drug related problems and cost burden on the healthcare system (Alhawassi T, 2019). Clinical studies show there is high prevalence of PIMs among elderly, ranging between $53.5 \%$ to 58.4\%, which is consistent with the results of this study (Zhang X, 2017) (Ní Chróinín D, 2016) (Endres H, 2016). The prevalence of PIMs in this sample of the Lebanese population was apparently higher than that in other countries, especially for the PIMs to be avoided (80\%), and the PIMs to be used with caution (78.2\%). Reasons behind these results may intersect, where the absence of specific in-patient criteria to assess the use of medications for elderly patients in the assessed Lebanese hospitals could be the main one. The absence of clinical pharmacists in the assessed hospitals may have contributed to these results, where the comprehensive medication reviews clinical pharmacists do, has been shown to improve overall patient health and alleviate health care burdens (Nemes S, 2009). Previous studies strongly support the clear role for pharmacists in working directly or collaboratively to improve medication use and management in older population (Lee J, 2015). Pharmacist integration into a multidisciplinary team has been shown to have a positive impact in the management of a variety of different disease states. Different assessment tools or versions may also contribute to such difference. Also, a marked difference in the prevalence of PIMs was shown when applying two versions of beers criteria (2003 and 2012) on the same population, as results varied by a $9 \%$ increase ( $48 \%$ versus $59 \%$ respectively), which could be another cause for the results variation (Baldoni ADO, 2014).

Being the most prevalent PIM to be avoided (60\%), proton pump inhibitors (PPIs) are among the most used medications in hospitals, while antipsychotics (48\%) and diuretics (31\%) are among the most common PIMs to be used with caution. Long term use of PPIs without a specific clinical indication is considered a PIM in older adults, increasing the risk of C. diff infection, bone loss, or fractures, and should be carefully prescribed and monitored (Trifan A, 2017) $($ Zhou B, 2015) especially that age-related bone loss with marked increase in bone resorption is evident in both genders, along with a reduction in bone formation and initial fall in bone mineral density (Demontiero O, 2012). These findings are consistent with other studies conducted in different countries, showing that PPI's are among the most prevalent PIMs (Zhang X, 2017) (Bhatt A, 2019), while antipsychotics and diuretics are among the most common PIMs to be used with caution (Vieira de Lima T, 2013) (Mann E, 2009). CNS active drugs taken by elderly in this sample were mainly SSRIs, antipsychotics, BZD, TCAs and opioids, while two main drug-drug interactions were noticed, which may be alarming. First, the administration of 3 or more CNS active drugs concomitantly (ex: SSRIs, TCAs, BDZ) can increase the risk of falls/fractures (Hanlon J, 2017). Second, the use of 2 anticholinergics at the same time (ex: amitriptyline, trihexyphenidyl, hyoscyamine) which can increase the risk of cognitive decline (Dauphinot V, 2017). CNS active drugs are highly associated with increased risk of falls in nursing home residents especially with older population (Hanlon J, 2017), and thus precaution measures should be taken into consideration.

The most important independent predictor for having a PIM in the tested population was found to be polypharmacy, especially when the majority of patients suffer from concomitant chronic conditions. It is an area of concern for elderly due to the greater risk for adverse drug reactions, drug-drug interactions, prescribing cascades and risk of falls (Dagli R J, 2014) and can lead to decreased medication compliance, poor quality of life and unnecessary drug expenses 
(Abdulraheem I, 2013). A strong association between polypharmacy and different types of PIMs has been reported in this study and in other studies (Alhawassi T, 2019) (Napolitano F, 2013). Patients with multiple comorbid conditions, recent hospitalizations and counseled by multiple physicians are more likely to be on multiple medications, and thus increased opportunities to have a prescribed PIM (Bao Y, 2011). A systematic review aiming to quantify the extent of inappropriate prescription to elderly persons in the primary care setting concluded that one in five prescriptions to elderly is inappropriate, despite the attention that has been directed to the quality of prescription (Opondo D, 2012). The findings in this study sheds the light more on the importance of reducing the number of prescribed drugs for which there is no clinical need, to diminish the prevalence of drug inappropriateness in elderly patients. The association between PIM use and certain pathologies could be an important marker of incorrect disease management and increased tendency for irrational prescriptions (Wawruch M., 2018) Several medical conditions found to be directly related to prescribed PIMs, such as insomnia, schizophrenia, dementia and falls.

The need to adopt different interventions by all healthcare professionals to reduce the tendency of prescribing PIMs in elderly is essential. An overview aiming to identify and critically evaluate systematic reviews addressing the effectiveness of such interventions showed the potential benefits of different strategies (Santos N, 2019). Those interventions included: computerized systems to support drug prescription and dispensing, training on the use of validated tools for the detection of PIMs, procedures and explicit routines for medications review, continuing education for health professionals and geriatric medicine services; combined interventions reveal better results than isolated ones.

To our knowledge, this is the first study in a developing country like Lebanon that investigates the prevalence of PIMs for in-patients, and particularly in Bekaa area, were no university hospitals are found. Thus, it was essential to assess the prevalence of such inappropriateness in areas were medications' safety and efficacy protocols are uncommon, underestimated in practice, or even absent. A validated and updated criterion adopted by the American Geriatric Society (AGS) was used in assessment, which gives the study more strength and validity. The primary limitation of this study is the small sample size. Data was collected during the Covid-19 pandemic, where approaching patients and files was low. Small sample sizes usually lead to the overestimation of odds ratio and to the reduction in the statistical power of a study (Deziel C, 2020). Also, only hospitalized patients were included which is not representative of community-based aged patients who were recently discharged. The last limitation is related to the nature of the study; it is cross sectional which doesn't allow us to determine the presence or absence of a temporal link between PIMs use and its determinants.

\section{Conclusion}

High prevalence of potentially inappropriate medications in the Lebanese hospitalized elderly population was shown to be evident. There was a strong association between potentially inappropriate medications use and polypharmacy, which is considered a serious challenge in the geriatric healthcare sector. These findings underscore the need to improve the medication prescription quality for the elderly by implementing clinical guidelines, reducing the number of unnecessary prescribed medications when possible, and assisting physicians in delivering appropriate medications. Pharmacists, working in a multidisciplinary team can play a significant role in reducing PIMs use among elderly, and thus their absence may affect the overall clinical outcomes, safety, and efficacy of the prescribed drugs. This role can be illustrated in 
reviewing the patients' prescriptions, detecting PIMs and recommending appropriate drug use, and creating changes in prescribing practices in accordance with guidelines from the literature.

\section{Declaration}

\section{Ethics approval and consent to participate}

This study design and methods were carried out in accordance with relevant guidelines and regulations under Ethics approval and consent to participate. Ethical approval was obtained from the School of Pharmacy at the Lebanese International University and the hospitals' administrations. Written informed consent was also obtained.

\section{Consent of publication}

Not applicable

\section{Availability of Data and Material}

Data sharing not applicable to this article as no datasets were generated or analyzed during the current study

\section{Conflicts of interest}

The authors declare that they have no competing interests

\section{Funding}

None

\section{Authors' contributions}

The authors confirm contribution to the paper as follows: study conception and design: M.H, M.H, A.C, S.Y, M.R. Data collection, analysis and interpretation of results: M.H, M.H, A.C, M.M, N.M. Draft manuscript preparation and revision: all authors: M.H, M.H, A.C, S.Y, N.M, M.M, M.R.

\section{Acknowledgments}

None 


\section{References}

1) Abdulraheem, I. (2013). Polypharmacy: A Risk Factor for Geriatric Syndrome, Morbidity \& Mortality. Journal Of Aging Science, 1:2. doi: 10.4172/2329-8847.1000e103

2) Ageing and health. (2018). Retrieved from https://www.who.int/news-room/fact-sheets/detail/ageing-and-health

3) Alhawassi, T., Alatawi, W., \& Alwhaibi, M. (2019). Prevalence of potentially inappropriate medications use among older adults and risk factors using the 2015 American Geriatrics Society Beers criteria. BMC Geriatrics, 19(1). doi: 10.1186/s12877-019-1168-1

4) American Geriatrics Society 2019 Updated AGS Beers Criteria ${ }^{\circledR}$ for Potentially Inappropriate Medication Use in Older Adults. (2019). Journal Of The American Geriatrics Society, 67(4), 674-694. doi: 10.1111/jgs.15767

5) Baldoni ADO, Ayres LR, Martinez EZ, Dewulf NDLS, Dos Santos V, Pereira LRL (2014). Factors associated with potentially inappropriate medications use by the elderly according to Beers criteria 2003 and 2012. Int J Clin Pharm. 2014;36(2):316-324. doi: 10.1007/s11096-013-9880-y.

6) Bao, Y., Shao, H., Bishop, T., Schackman, B., \& Bruce, M. (2011). Inappropriate Medication in a National Sample of US Elderly Patients Receiving Home Health Care. Journal Of General Internal Medicine, 27(3), 304310. doi: 10.1007/s11606-011-1905-4

7) Bhatt A, Paul S, Krishnamoorthy S, Baby B, Mathew A, Nair B. (2019). Potentially inappropriate medications prescribed for older persons: A study from two teaching hospitals in Southern India. J Family Community Med., 26(3): 187-192.. doi: 10.4103/jfcm.JFCM_81_19

8) Dagli, R. J., \& Sharma, A. (2014). Polypharmacy: a global risk factor for elderly people. Journal of international oral health: $\mathrm{JIOH}, 6(6)$, i-ii.

9) Dauphinot, V., Mouchoux, C., Veillard, S., Delphin-Combe, F., \& Krolak-Salmon, P. (2017). Anticholinergic drugs and functional, cognitive impairment and behavioral disturbances in patients from a memory clinic with subjective cognitive decline or neurocognitive disorders. Alzheimer's Research \& Therapy, 9(1). doi: 10.1186/s13195-017-0284-4

10) Demontiero, O., Vidal, C., \& Duque, G. (2012). Aging and bone loss: new insights for the clinician. Therapeutic advances in musculoskeletal disease, 4(2), 61-76. Doi: 10.1177/1759720X11430858

11) Deziel, Chris. (2020, October 14). The Effects of a Small Sample Size Limitation. sciencing.com. Retrieved from https://sciencing.com/effects-small-sample-size-limitation-8545371.html

12) Endres, H., Kaufmann-Kolle, P., Steeb, V., Bauer, E., Böttner, C., \& Thürmann, P. (2016). Association between Potentially Inappropriate Medication (PIM) Use and Risk of Hospitalization in Older Adults: An Observational Study Based on Routine Data Comparing PIM Use with Use of PIM Alternatives. PLOS ONE, 11(2), e0146811. doi: 10.1371/journal.pone.0146811

13) For Older People, Medications Are Common; Updated AGS Beers Criteria ${ }^{\circledR}$ Aims to Make Sure They're Appropriate, Too | American Geriatrics Society. (2019). Retrieved from https://www.americangeriatrics.org/media-center/news/older-people-medications-are-common-updated-ags-beerscriteriar-aims-make-sure

14) Hanlon, J., Zhao, X., Naples, J., Aspinall, S., Perera, S., \& Nace, D. et al. (2017). Central Nervous System Medication Burden and Serious Falls in Older Nursing Home Residents. Journal Of The American Geriatrics Society, 65(6), 1183-1189. doi: 10.1111/jgs.14759 
15) Howard-Thompson A, Farland MZ, Byrd DC, Airee A, Thomas J, Campbell J, Cassidy R, Morgan T, Suda KJ. (2013) Pharmacist-physician collaboration for diabetes care: cardiovascular outcomes. Ann Pharmacother. 2013 Nov;47(11):1471-7. doi: 10.1177/1060028013504738.

16) Lavan, A. H., \& Gallagher, P. (2016). Predicting risk of adverse drug reactions in older adults. Therapeutic advances in drug safety, 7(1), 11-22. Doi: 10.1177/2042098615615472

17) Lee J, Alshehri S, Kutbi H, Martin J. (2015). Optimizing pharmacotherapy in elderly patients: the role of pharmacists. Integr Pharm Res Pract. 2015;4:101-111. doi: 10.2147/IPRP.S70404

18) Lu WH, Wen YW, Chen LK, Hsiao FY. Effect of polypharmacy, potentially inappropriate medications and anticholinergic burden on clinical outcomes: a retrospective cohort study (2015). CMAJ ;187(4):E130-E137. doi: 10.1503/cmaj.141219.

19) Mann, E., Köpke, S., Haastert, B., Pitkälä, K., \& Meyer, G. (2009). Psychotropic medication use among nursing home residents in Austria: a cross-sectional study. BMC Geriatrics, 9(1). doi: 10.1186/1471-2318-9-18

20) Napolitano, F., Izzo, M., Di Giuseppe, G., \& Angelillo, I. (2013). Frequency of Inappropriate Medication Prescription in Hospitalized Elderly Patients in Italy. Plos ONE, 8(12), e82359. doi: 10.1371/journal.pone.0082359

21) Nemes, S., Jonasson, J. M., Genell, A., \& Steineck, G. (2009). Bias in odds ratios by logistic regression modelling and sample size. BMC medical research methodology, 9, 56. doi: 10.1186/1471-2288-9-56

22) Ní Chróinín, D., Neto, H., Xiao, D., Sandhu, A., Brazel, C., \& Farnham, N. et al. (2016). Potentially inappropriate medications (PIMs) in older hospital in-patients: Prevalence, contribution to hospital admission and documentation of rationale for continuation. Australasian Journal On Ageing, 35(4), 262-265. doi: 10.1111/ajag.12312

23) Opondo, D., Eslami, S., Visscher, S., de Rooij, S., Verheij, R., Korevaar, J., \& Abu-Hanna, A. (2012). Inappropriateness of Medication Prescriptions to Elderly Patients in the Primary Care Setting: A Systematic Review. Plos ONE, 7(8), e43617. doi: 10.1371/journal.pone.0043617

24) Reich, O., Rosemann, T., Rapold, R., Blozik, E., \& Senn, O. (2014). Potentially Inappropriate Medication Use in Older Patients in Swiss Managed Care Plans: Prevalence, Determinants and Association with Hospitalization. Plos ONE, 9(8), e105425. doi: 10.1371/journal.pone.0105425

25) Santos, N., Marengo, L. L., Moraes, F., \& Barberato Filho, S. (2019). Interventions to reduce the prescription of inappropriate medicines in older patients. Revista de saude publica, 53, 7. doi: 10.11606/S1518$\underline{8787.2019053000781}$

26) Trifan, A., Stanciu, C., Girleanu, I., Stoica, O., Singeap, A., \& Maxim, R. et al. (2017). Proton pump inhibitors therapy and risk of Clostridium difficile infection: Systematic review and meta-analysis. World Journal Of Gastroenterology, 23(35), 6500-6515. doi: 10.3748/wjg.v23.i35.6500

27) Vieira de Lima, T., Garbin, C., Garbin, A., Sumida, D., \& Saliba, O. (2013). Potentially inappropriate medications used by the elderly: prevalence and risk factors in Brazilian care homes. BMC Geriatrics, 13(1). doi: $10.1186 / 1471-2318-13-52$

28) Wawruch, M., Fialova, D., Zikavska, M., Wsolova, L., Jezova, D., \& Kuzelova, M. et al. (2008). Factors influencing the use of potentially inappropriate medication in older patients in Slovakia. Journal Of Clinical Pharmacy And Therapeutics, 33(4), 381-392. doi: 10.1111/j.1365-2710.2008.00929.x

29) Zhang, X., Zhou, S., Pan, K., Li, X., Zhao, X., \& Zhou, Y. et al. (2017). Potentially inappropriate medications in hospitalized older patients: a cross-sectional study using the Beers 2015 criteria versus the 2012 criteria. Clinical Interventions In Aging, Volume 12, 1697-1703. doi: 10.2147/cia.s146009

30) Zhou, B., Huang, Y., Li, H., Sun, W., \& Liu, J. (2015). Proton-pump inhibitors and risk of fractures: an update meta-analysis. Osteoporosis International, 27(1), 339-347. doi: 10.1007/s00198-015-3365-x 
List of tables and figures:

\begin{tabular}{|c|c|}
\hline Characteristics & $\mathbf{N}(\%)$ \\
\hline \multicolumn{2}{|l|}{ Age } \\
\hline $65-69$ & $40(37 \%)$ \\
\hline $70-74$ & \begin{tabular}{|l|l}
$17(15.7 \%)$ \\
\end{tabular} \\
\hline $75-79$ & $13(12 \%)$ \\
\hline$>=80$ & $38(35.2 \%)$ \\
\hline \multicolumn{2}{|l|}{ Gender } \\
\hline Male & $19(17.4 \%)$ \\
\hline Female & $90(82.6)$ \\
\hline \multicolumn{2}{|l|}{ Marital status } \\
\hline Single & $3(3.1 \%)$ \\
\hline Married & $92(93.8 \%)$ \\
\hline Widowed/separated & $3(3.1 \%)$ \\
\hline \multicolumn{2}{|l|}{ Bedridden } \\
\hline No & $89(82.4 \%)$ \\
\hline Yes & $19(17.6 \%)$ \\
\hline \multicolumn{2}{|l|}{ Smoking status } \\
\hline No & $59(55.7 \%)$ \\
\hline Yes & $47(44.3 \%)$ \\
\hline \multicolumn{2}{|l|}{ Alcohol status } \\
\hline No & $103(99 \%)$ \\
\hline Yes & $1(1 \%)$ \\
\hline \multicolumn{2}{|l|}{ Polypharmacy } \\
\hline No & $29(26.4 \%)$ \\
\hline Yes & $81(73.6 \%)$ \\
\hline
\end{tabular}

Table 1: Participants' socioeconomic data

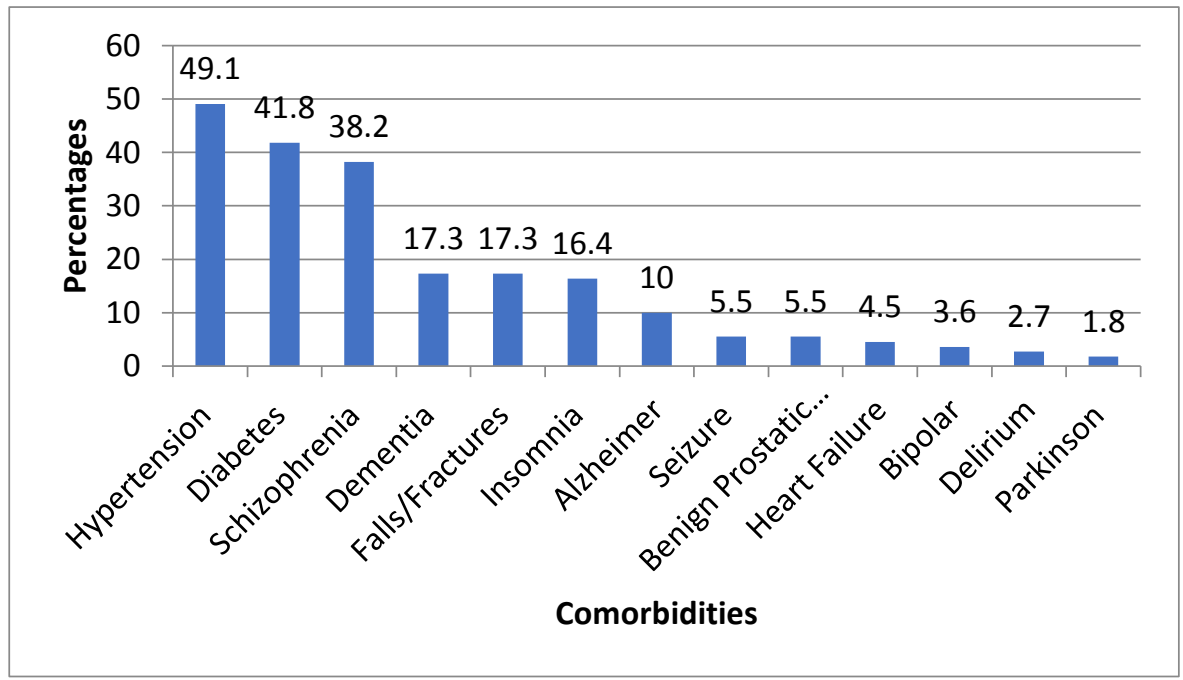

Figure 1: Participants' comorbidities 


\begin{tabular}{|l|l|}
\hline Type of PIM & N (\%) \\
\hline PIMs in total & $105(95.5 \%)$ \\
\hline PIMs to be avoided & $88(80 \%)$ \\
\hline PIMs to be used with caution & $86(78.2 \%)$ \\
\hline $\begin{array}{l}\text { PIMs having drug-disease or drug syndrome } \\
\text { interaction that may exacerbate the disease or } \\
\text { syndrome }\end{array}$ & $25(22.7 \%)$ \\
\hline $\begin{array}{l}\text { PIMs having clinically important drug-drug } \\
\text { interactions that should be avoided }\end{array}$ & $17(15.5 \%)$ \\
\hline
\end{tabular}

Table 2: PIMs

\begin{tabular}{|c|c|}
\hline PIMs & $\mathrm{N}(\%)$ \\
\hline \multicolumn{2}{|l|}{ Anticholinergics } \\
\hline First generation antihistamines & $13(11.8 \%)$ \\
\hline \multicolumn{2}{|l|}{ Antiparkinsonian agents } \\
\hline Trihexyphenidyl & $14(12.7 \%)$ \\
\hline \multicolumn{2}{|l|}{ Antispasmodics } \\
\hline Scopolamine & $2(1.8 \%)$ \\
\hline \multicolumn{2}{|l|}{ Cardiovascular } \\
\hline $\begin{array}{l}\text { Peripheral alpha- } 1 \text { blockers for the treatment of } \\
\text { hypertension }\end{array}$ & $1(0.9 \%)$ \\
\hline Digoxin & $1(0.9 \%)$ \\
\hline \multicolumn{2}{|l|}{ Central nervous system } \\
\hline Antidepressants & $2(1.8 \%)$ \\
\hline $\begin{array}{l}\text { Antipsychotics, first (conventional) and second } \\
\text { (atypical) generations }\end{array}$ & $6(5.5 \%)$ \\
\hline Benzodiazepines & $14(12.7 \%)$ \\
\hline \multicolumn{2}{|l|}{ Endocrine } \\
\hline Insulin & $4(3.6 \%)$ \\
\hline Sulfonylureas, long acting & $4(4.5 \%)$ \\
\hline \multicolumn{2}{|l|}{ Gastrointestinal } \\
\hline Proton-pump inhibitors & $66(60 \%)$ \\
\hline Metoclopramide & $2(1.8 \%)$ \\
\hline \multicolumn{2}{|l|}{ Pain medications } \\
\hline Meperidine & $1(0.9 \%)$ \\
\hline Non-cyclooxygenase-selective NSAIDs, oral & $1(0.9 \%)$ \\
\hline
\end{tabular}

Table 3: PIMs to be avoided

\begin{tabular}{|l|l|}
\hline PIMs to be used with caution & N (\%) \\
\hline Diuretics & $34(30.9 \%)$ \\
\hline SSRIs & $17(15.5 \%)$ \\
\hline Antipsychotics & $53(48.2 \%)$ \\
\hline Aspirin & $17(15.5 \%)$ \\
\hline Carbamazepine & $1(0.9 \%)$ \\
\hline TCAs & $3(2.7 \%)$ \\
\hline Opioids & $1(0.9 \%)$ \\
\hline Rivaroxaban & $1(0.9 \%)$ \\
\hline
\end{tabular}


Table 4: PIMs to be used with caution 


\begin{tabular}{|c|c|c|c|c|c|}
\hline & \multicolumn{2}{|c|}{$\begin{array}{l}\text { With PIMs } \\
\text { to be } \\
\text { avoided }\end{array}$} & \multicolumn{2}{|c|}{$\begin{array}{l}\text { Without } \\
\text { PIMs to be } \\
\text { avoided }\end{array}$} & \multirow[t]{2}{*}{ P-value } \\
\hline & $\mathbf{N}$ & $\%$ & $\mathbf{N}$ & $\%$ & \\
\hline Total & 88 & 80 & 22 & 20 & \\
\hline Gender & & & & & 0.4 \\
\hline Male & 17 & 89.5 & 2 & 10.5 & \\
\hline Female & 70 & 77.8 & 20 & 22.2 & \\
\hline Age & & & & & 0.2 \\
\hline $65-69$ & 31 & 77.5 & 9 & 22.5 & \\
\hline $70-74$ & 11 & 64.7 & 6 & 35.3 & \\
\hline $75-79$ & 12 & 92.3 & 1 & 7.7 & \\
\hline$>=80$ & 33 & 86.8 & 5 & 13.2 & \\
\hline Marital status & & & & & 0.07 \\
\hline Single & 29 & 69 & 13 & 31 & \\
\hline Married & 24 & 82.8 & 5 & 17.2 & \\
\hline Widowed/separated & 28 & 90.3 & 3 & 9.7 & \\
\hline Smoking & & & & & 1 \\
\hline No & 47 & 79.7 & 12 & 20.3 & \\
\hline Yes & 38 & 80.9 & 9 & 19.1 & \\
\hline Alcohol & & & & & 1 \\
\hline No & 84 & 81.6 & 19 & 18.4 & \\
\hline Yes & 1 & 100 & 0 & 0 & \\
\hline Polypharmacy & & & & & $<0.001$ \\
\hline No & 16 & 55.2 & 13 & 44.8 & \\
\hline Yes & 72 & 88.9 & 9 & 11.1 & \\
\hline Bedridden & & & & & 1 \\
\hline No & 72 & 80.9 & 17 & 19.1 & \\
\hline Yes & 15 & 78.9 & 4 & 21.1 & \\
\hline HF & & & & & 0.3 \\
\hline No & 85 & 81 & 20 & 19 & \\
\hline Yes & 3 & 60 & 2 & 40 & \\
\hline HTN & & & & & 0.002 \\
\hline No & 38 & 67.9 & 18 & 32.1 & \\
\hline Yes & 50 & 92.6 & 4 & 7.4 & \\
\hline DM & & & & & 0.02 \\
\hline No & 46 & 71.9 & 18 & 28.1 & \\
\hline Yes & 42 & 91.3 & 4 & 8.7 & \\
\hline Seizure & & & & & 1 \\
\hline No & 83 & 79.8 & 21 & 20.2 & \\
\hline Yes & 5 & 83.3 & 1 & 16.7 & \\
\hline Delirium & & & & & 1 \\
\hline No & 85 & 79.4 & 22 & 20.6 & \\
\hline Yes & 3 & 100 & 0 & 0 & \\
\hline Dementia & & & & & 1 \\
\hline No & 73 & 80.2 & 18 & 19.8 & \\
\hline Yes & 15 & 78.9 & 4 & 21.1 & \\
\hline Falls & & & & & 0.01 \\
\hline No & 69 & 75.8 & 22 & 24.2 & \\
\hline Yes & 19 & 100 & 0 & 0 & \\
\hline Insomnia & & & & & 0.1 \\
\hline
\end{tabular}




\begin{tabular}{|c|l|l|l|l|l|}
\hline No & 71 & 77.2 & 21 & 22.8 & \\
\hline Yes & 17 & 94.4 & 1 & 5.6 & \\
\hline Parkinson & & & & & 0.4 \\
\hline No & 87 & 80.6 & 21 & 19.4 & \\
\hline Yes & 1 & 50 & 1 & 50 & \\
\hline Alzheimer's Disease & & & & & 0.5 \\
\hline No & 80 & 80.8 & 19 & 19.2 & \\
\hline Yes & 8 & 72.7 & 3 & 27.3 & \\
\hline Bipolar No & & & & & 0.03 \\
\hline Yes & 87 & 82.1 & 19 & 17.9 & \\
\hline Schizophrenia & 1 & 25 & 3 & 75 & \\
\hline No & & & & & 0.09 \\
\hline Yes & 58 & 85.3 & 10 & 14.7 & \\
\hline BPH & 30 & 71.4 & 12 & 28.6 & \\
\hline No & & & & & 0.6 \\
\hline Yes & 62 & 78.8 & 22 & 21.2 & \\
\hline
\end{tabular}

Table 5: Variables and conditions associated with PIMs 


\begin{tabular}{|c|c|c|c|c|c|c|c|}
\hline & \multirow[t]{2}{*}{ Type of PIM } & \multicolumn{2}{|c|}{ With PIM } & \multicolumn{2}{|c|}{$\begin{array}{l}\text { Without } \\
\text { PIM }\end{array}$} & \multicolumn{2}{|c|}{ Multivariable Analysis } \\
\hline & & $\mathbf{N}$ & $\%$ & $\mathbf{N}$ & $\%$ & OR $(95 \% \mathrm{CI})$ & P-value \\
\hline \multirow[t]{3}{*}{ Age } & PIMs to be avoided & & & & & & 0.04 \\
\hline & $65-69$ & 31 & 77.5 & 9 & 22.5 & Reference & \\
\hline & $70-74$ & 11 & 64.7 & 6 & 35.3 & $0.11(0.01,0.92)$ & \\
\hline \multirow{9}{*}{ Polypharmacy } & PIMs to be avoided & & & & & & 0.001 \\
\hline & No & 16 & 55.2 & 13 & 44.8 & Reference & \\
\hline & Yes & 72 & 88.9 & 9 & 11.1 & $16.82(2.97,95.18)$ & \\
\hline & PIMs to be used with caution & & & & & & 0.05 \\
\hline & No & 17 & 58.6 & 12 & 41.4 & Reference & \\
\hline & Yes & 69 & 85.2 & 12 & 14.8 & $3.46(1.01,11.81)$ & \\
\hline & PIMs of Drug-disease interaction & & & & & & 0.04 \\
\hline & No & 3 & 10.3 & 26 & 89.7 & Reference & \\
\hline & Yes & 22 & 27.2 & 59 & 72.8 & $12.91(1.09,152.41)$ & \\
\hline \multirow[t]{3}{*}{ Dementia } & PIMs of Drug-disease interaction & & & & & & 0.01 \\
\hline & No & 14 & 15.4 & 77 & 84.6 & Reference & \\
\hline & Yes & 11 & 57.9 & 8 & 22.1 & $40.88(3,556.71)$ & \\
\hline \multirow[t]{6}{*}{ Falls } & PIMs to be used with caution & & & & & & 0.05 \\
\hline & No & 68 & 74.7 & 23 & 25.3 & Reference & \\
\hline & Yes & 18 & 94.7 & 1 & 5.3 & $8.92(1,79.55)$ & \\
\hline & PIMs of Drug-disease interaction & & & & & & $<0.001$ \\
\hline & No & 12 & 13.2 & 79 & 86.8 & Reference & \\
\hline & Yes & 13 & 68.4 & 6 & 31.6 & 48.94(7.75,308.87) & \\
\hline \multirow[t]{6}{*}{ Insomnia } & PIMs to be avoided & & & & & & 0.04 \\
\hline & No & 71 & 77.2 & 21 & 22.8 & Reference & \\
\hline & Yes & 17 & 94.4 & 1 & 5.6 & $15.80(1.16,215.18)$ & \\
\hline & PIMs to be used with caution & & & & & & 0.02 \\
\hline & No & 76 & 82.6 & 16 & 17.4 & Reference & \\
\hline & Yes & 10 & 55.6 & 8 & 44.4 & $0.14(0.03,0.69)$ & \\
\hline \multirow[t]{9}{*}{ Schizophrenia } & PIMs to be avoided & & & & & & 0.03 \\
\hline & No & 58 & 85.3 & 10 & 14.7 & Reference & \\
\hline & Yes & 30 & 71.4 & 12 & 28.6 & $0.14(0.03,0.79)$ & \\
\hline & PIMs to be used with caution & & & & & & 0.003 \\
\hline & No & 45 & 66.2 & 23 & 33.8 & Reference & \\
\hline & Yes & 41 & 97.6 & 1 & 2.4 & $28.75(3.10,266.93)$ & \\
\hline & PIMs of Drug-disease interaction & & & & & & 0.002 \\
\hline & No & 2 & 2.9 & 66 & 97.1 & Reference & \\
\hline & Yes & 15 & 35.7 & 27 & 64.3 & $13.54(2.55,71.81)$ & \\
\hline
\end{tabular}

Table 6: Combined significant results of the multivariate analysis 
Figures

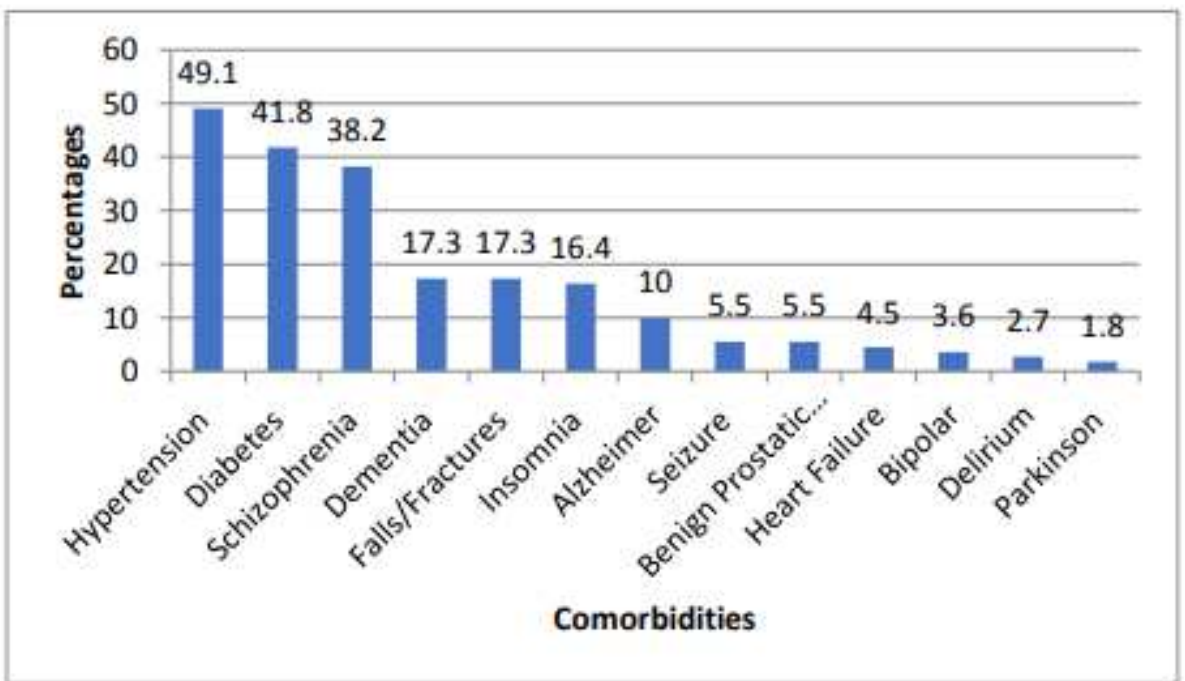

Figure 1

Participants' comorbidities 